winged watchmen draw attention to themselves by making particular calls.

Andrew Radford at the University of Bristol, UK, and his colleagues observed groups of pied babblers (Turdoides bicolor; pictured right) in the Kalahari in Africa, and recorded the sentinels' sounds. Playing the calls back, they found that the group ate more when a watchman sang; the flock also spread out more and looked up less often.

Because the foraging gains of other birds seem to explain the behaviour, the authors argue that it is an example of cooperation. The close kinship between guard and guarded suggests that sentinel duty is a means by which individuals increase their genetic contribution to future generations.

\section{MOLECULAR PHYSICS}

\section{Slicing the ice}

J. Phys. Chem. B doi:10.1021/jp073870c (2008) Ice can generate a voltage when heated or cooled, say Richard Bell at Pennsylvania State University in Altoona, James Cowin of Pacific Northwest National Laboratory in Richland, Washington, and their co-workers. The trick is to deposit ions at $-113^{\circ} \mathrm{C}$ onto a 1-micrometre-thick ice film, thereby charging the surface of the film and rotating its water molecules, which become locked in position when the film is later cooled.

Normally, water molecules are randomly oriented in ice. Each one has an asymmetrical distribution of positive and negative charge that could create a voltage were many water molecules to become frozen in alignment. Cowin's team's method achieves a voltage as large as those generated by commercial materials and that varies steeply and

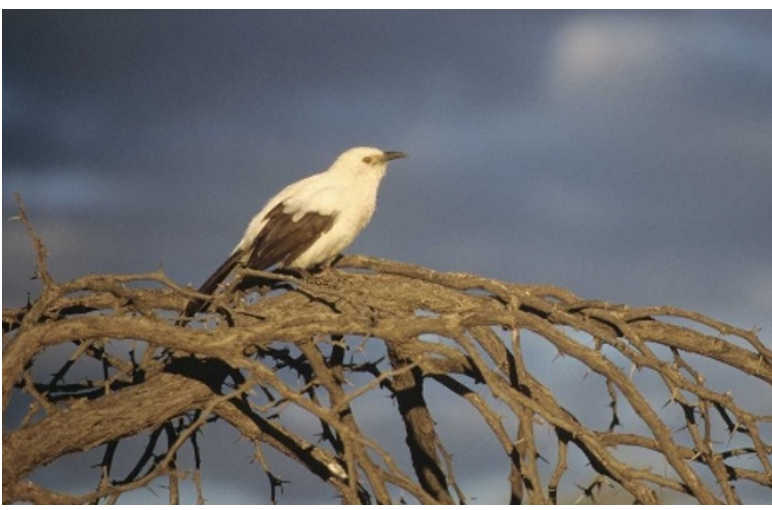

ATMOSPHERIC SCIENCE

Jetting away

Geophys. Res. Lett. 35, L08803 (2008)

Three bands of fast-moving wind known as jet streams - have shifted position in recent decades, according to a new analysis of weather data that were collected between 1979 and 2001 .

Shifts in the jet streams are expected in a changing climate, and the work by Cristina Archer and Ken Caldeira, of the Carnegie Institution of Washington in Stanford, California,

reversibly with temperature.

The same process could cause an electrostatic attraction between icy grains exposed to cosmic rays in space, promoting their aggregation into proto-planetary lumps.

\section{VIROLOGY}

\section{Rubbish imitation}

Science 320, 531-535 (2008)

The vaccinia virus had a dirty secret.

Researchers in Switzerland have revealed that it dupes cells into taking it in by mimicking the detritus that many types of cell would normally mop up.

The work is important because vaccinia typifies pox viruses such as smallpox. Jason Mercer and Ari Helenius of ETH Zurich watched fluorescently labelled virus particles trigger the membranes of their target cells to develop a spherical bulge called a 'bleb'. Blebbing proved crucial for infection, and a fat molecule called phosphatidylserine in the viral membrane proved crucial for virus-induced blebbing. Because the process normally deals with 'rubbish' in healthy cells, it flies under the radar of the immune system and thus enables pox viruses to evade detection as they spread between cells. looked at observational records for any such effects. They report that the northern jet stream weakened, and that one of the southern jet streams weakened whereas the other strengthened. All three jet streams moved higher in altitude and closer to the poles, by about 19 kilometres per decade.

\section{NEUROSCIENCE}

\section{Algal vision}

Nature Neurosci. doi: 10.1038/nn2117 (2008) Blind mice that had lost all the light receptors in their retinae have had their vision partly restored thanks to a light-sensitive ion channel from a green alga, Chlamydomonas reinhardtii.

Botond Roska of the Friedrich Miescher Institute for Biomedical Research in Basel, Switzerland, and his colleagues inserted the gene for this ion channel into the DNA of specific mouse retinal cells, the ON bipolar cells. Formerly blind mice with these cells gained rudimentary sight because light opened algal ion channels in the modified retinal neurons, allowing positively charged ions to flood in and a signal to be sent to the visual region of the brain. The mice fled from strong light and responded to moving grid patterns.

\section{JOURNAL CLUB}

\section{Kristi Anseth \\ University of Colorado, Boulder}

\section{A biologist looks to 'click chemistry' for better three- dimensional tissue models.}

A hot topic in organic chemistry is the development of ways to neatly home in on a particular chemical group and cause a reaction to proceed extremely efficiently under mild conditions. Such highly optimized reactions have been grouped under the term 'click chemistry'. A commonly cited example involves functional groups called azides and alkynes, which react to form triazoles with the aid of a copper catalyst.

Click chemistry has all sorts of uses, although few are in biology because the technique relies on toxic metal catalysts. However, Carolyn Bertozzi and her colleagues at the University of California, Berkeley, and the nearby Lawrence Berkeley National Laboratory recently demonstrated copper-free click chemistry in a living system (J. M. Baskin et al. Proc. Natl Acad. Sci. USA 104, 16793-16797; 2007). These authors selectively - and rapidly - labelled cell-surface polysaccharides with with triazole bound to a fluorescent probe. The technique allows real-time imaging of cell surface molecules that are otherwise impossible to achieve.

This research throws open the door for a host of new applications for click chemistry. As a tissue engineer, I am particularly excited about exploiting it to make better gels for three-dimensional cell culture.

Physiological processes are routinely guided by interactions between cells and their tissue environment. Thus, a major hurdle in tissue regeneration is knowing which biochemical signals must be recapitulated in cell culture, and how to present them at the appropriate time and place. Copper-free click chemistry could allow scientists to synthesize materials that deliver these signals at times that are governed by the physiological conditions in which the material resides. Next on my wish list is the ability to control the spatial organization of these reactions.

Discuss this paper at http://blogs. nature.com/nature/journalclub 